\title{
A Comprehensive Review on the Effects of Laser Photobiomodulation on Skeletal Muscle Fatigue in Spastic Patients
}

\author{
Sadi F. Stamborowski $\mathbb{D}^{1}{ }^{1}$ Fernanda Púpio Silva Lima $\mathbb{D}^{1}{ }^{1}$ Patrícia Sardinha Leonardo, ${ }^{2}$ \\ and Mário Oliveira Lima $\oplus^{1}$ \\ ${ }^{1}$ Laboratório de Engenharia de Reabilitação Sensório Motora, Institute of Research and Development (IPßD), Universidade do Vale \\ do Paraíba (UNIVAP), São José dos Campos, 12244-000 São Paulo, Brazil \\ ${ }^{2}$ Faculty of Health Sciences, Universidade do Vale do Paraíba (UNIVAP), São José dos Campos, 12244-000 São Paulo, Brazil
}

Correspondence should be addressed to Sadi F. Stamborowski; sadifs@gmail.com

Received 14 January 2021; Accepted 23 March 2021; Published 8 April 2021

Academic Editor: Alberto Ãlvarez-Gallegos

Copyright (C) 2021 Sadi F. Stamborowski et al. This is an open access article distributed under the Creative Commons Attribution License, which permits unrestricted use, distribution, and reproduction in any medium, provided the original work is properly cited.

\begin{abstract}
Peripheral muscle fatigue is a common experience in daily life. Every individual at some point in their life has realized the inability to maintain muscle contraction, a phenomenon known as fatigue. Interestingly, neurological patients with peripheral sequelae such as spastic muscle contraction are able to remain in a pattern of muscle contraction for prolonged periods. The effects of laser therapy are already recognized in muscle contraction to delay skeletal muscle fatigue, prolong physical activity, and reduce delayed onset muscle soreness. However, the effects of photobiomodulation on neurological patients with muscular spasticity are still not well established. The present literature review seeks to recognize articles about the application of laser irradiation, also known as photobiomodulation, to patients with muscle fatigue and/or spastic palsy. To perform a literature review, we used the systematic review methodology for the literature search. The following keywords were searched: (skeletal muscle fatigue) AND (spastic patients) AND (low-level laser therapy OR low intensity laser therapy OR low energy laser therapy OR LLLT OR LILT OR LELT OR infrared laser OR IR laser OR diode laser), and these were used for search on the following databases: PubMed, Embase, Web of Science, BIREME, Scopus, and SciELO. Besides that, a literature review concerning on muscle physiology, fatigue, and LLLT was made. No language filter was applied, and altogether, 689 papers were identified. A group of 3 physiotherapists and 01 pharmaceutical scientist performed the literature review, and every exclusion was confirmed by at least two reviewers. After inclusion and exclusion criteria, 128 studies were included in this review. Conclusion, the LLLT can contribute to the recovery of spastic patients and muscles in fatigue. However, the real effect of laser photobiomodulation on muscle spasticity remains to be established. Only a much reduced number of clinical trials have been performed with a small number of participants. There is a lack of clinical trials from different research groups that could help to understand and elucidate the effects of laser in prolonged muscle contraction in spastic palsy.
\end{abstract}

\section{Introduction}

Looking into the past, more specifically since the 1960s, it was consistently seen that low-level laser therapy (LLLT) could present positive effects on the muscle-skeletal system and related diseases such as joint inflammation, sports injuries, muscle fatigue, and lower back and neck pain among other conditions [1]. Photobiomodulation has been covering new areas of study, and with them, there is a range of possibilities for spastic patients, to reduce or eliminate muscle fatigue in some cases, especially in patients with traumatic brain injury, for example [2].

Previously, photomodulation was called a "low-level laser therapy" or LLLT, including light from light-emitting diodes (LEDs), lasers, and other light sources with wavelengths ranging from visible to infrared. It has also become an 


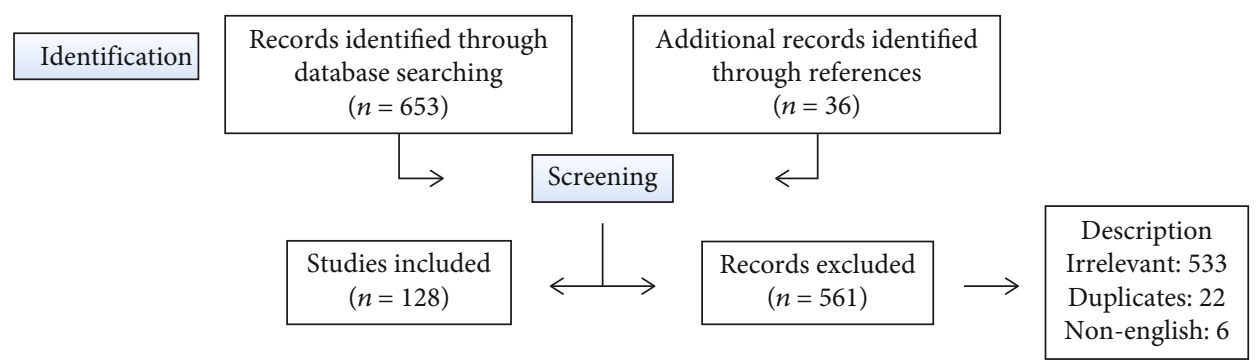

FIGURE 1: Schematic representation of the study selection to be included in the review.

increasingly mainstream treatment for muscle fatigue, especially in the areas of physical medicine and rehabilitation, in patients with a type of degenerative disease [3].

It is well known that there are dose responses to simultaneous applications of several different wavelengths in some cases, for example, to kill cancer cells and promote significantly faster healing in chronic and diabetic wounds and sports injuries, reduction of pain in arthritic joints and back and neck, reduction of inflammation by increasing the number of fibroblasts and myofibroblast, induction of the accumulation of collagen, and decrease of fatigue in the muscles in spastic patients [4]. Additionally, recent studies indicate that photobiomodulation can also become promising in clinical cases of patients suffering from myocardial infarction, stroke, brain injuries caused by trauma, or degenerative and spinal cord injury, with the last three triggering injuries in motor neurons and ending up directly affecting the muscles, causing spasms and finally fatigue and pain [5].

The wavelengths for photobiomodulation are more regularly used in the $500-700 \mathrm{~nm}$ range for treating superficial healing, while wavelengths between 800 and $1000 \mathrm{~nm}$ are used for deeper tissues and skeletal muscle fatigue [4].

This review focuses on the efficacy of photobiomodulation in muscle fatigue in spastic patients, its mechanisms of action, and how its efficacy may be increased by using multiple wavelengths. The review examines research related to the induction of muscle fatigue signaling pathways and the elimination of pain by the application of photobiomodulation and their mechanisms of action. Photobiomodulation application is making clear headway toward the development of a reliable and successful set of irradiation parameters for inducing significantly faster and more complete healing of illness related to muscles that does not respond to conventional treatment [3]. However, further work is required to optimize its therapeutic value to determine the integrative nature of fatigue in spastic patients.

\section{Methodology}

The following bibliographic databases were searched in MEDLINE via PubMed, Embase, Web of Science, BIREME, Scopus, and SciELO. The search strategy was (skeletal muscle fatigue) AND (spastic patients) AND (low-level laser therapy OR low intensity laser therapy OR low energy laser therapy OR LLLT OR LILT OR LELT OR infrared laser OR IR laser OR diode laser). No language filter was applied, and altogether, 689 papers were identified. A group of 3 physiothera- pists and 01 pharmaceutical scientist performed the literature review, and each exclusion was confirmed by at least two reviewers. After inclusion and exclusion criteria, 128 studies were included in this review.

Reviewers independently identified titles and abstracts relevant to applying LLLT to patients suffering from muscle fatigue and/or spastic. Full texts of the published articles, unpublished articles, and unpublished data of completely finished and analyzed studies were included. The reference list of full-text articles was also reviewed. Figure 1 illustrates the selection process for including studies.

\section{Homeostasis}

In the human body, one of the most plastic and dynamic tissues is the skeletal muscle. There is about $40 \%$ of the human total body weight in humans that is made up of skeletal muscle and is composed of $50-75 \%$ of all body proteins and accounts for $30-50 \%$ of the whole-body protein turnover. The composition of the muscle is mainly of water (75\%), protein $(20 \%)$, and other substances including inorganic salts, minerals, fats, and carbohydrates (5\%) [6].

The muscle mass depends on the conditional nutrition, hormonal condition, and the balance between physical activity/exercise and illness or injury. In addition, the balance between protein synthesis and degradation is extremely sensitive to factors that deregulate the different cellular compartments (structural, contractile, and regulatory); for this reason, it has received significant scientific attention because of their important contribution to mobility, contractility capacity, and functioning [7].

Skeletal muscle contributes significantly to multiple bodily functions, since mechanical function for converting chemical energy into mechanical energy to generate force and power, walking motion, or stand, besides allowing participation in social and sportive settings, maintains a possibility of functional independence. From a metabolic point of view, several skeletal muscle functions include a contribution to basal energy metabolism, like storage for important substrates such as amino acids and carbohydrates used by other tissues such as the skin, brain, and heart, and the production of heat for the maintenance of core temperature, and it is responsible for the consumption of the majority of oxygen and energy during physical activity and exercise [8].

Furthermore, amino acid release from muscle contributes to the maintenance of blood glucose levels during conditions 
of starvation, in that case, a person with a reduced muscle mass impairs the body's ability to respond to stress and chronic illness [9].

The architecture of skeletal muscle is characterized by myofibers or muscle cells and associated connective tissue. The structure of muscle is characterized by the number and size of individual muscle fibers, but any pathological infiltration by fat and connective tissue may alter this relationship $[10,11]$.

Observing the cellular level, the muscle fibers are multinucleated and postmitotic, and some part of each nucleus within a muscle fiber controls the type of protein synthesized in that specific region of the cell; these regions are known as nuclear domains and have a highly regulated, but not uniform, size [12]. Protein expression found in the adjacent domains of a single fiber appears to be coordinated in such a way that the type of protein, in this case, the myosin produced, is almost the same across the length of the fiber [13].

In the human body, there are several cell storage sites with stem cell potential; knowing this, it is important to note that skeletal muscle has cells of this nature, which are known as satellite cells and are located between the sarcolemma and the basal lamina and contribute to muscle growth, repair, and regeneration $[12,14]$. When these cells are activated by myogenic factors, satellite cells proliferate and differentiate into new muscle fibers and repair the local injury.

The functional unit of the muscle is divided into compatibilities and is separated by a dense connective tissue called a sarcolemma. The outermost layer that contemplates the bundles of muscular fibers is called epimisio. The perimeter consists of the grouping of fibers within and surrounded by another layer of connective tissue. In addition, there is a complex of several proteins associated with the sarcolemma and are usually connected to the myofilament of actin. A singlemuscle fiber has approximate dimensions of $100 \mu \mathrm{m}$ in diameter and $1 \mathrm{~cm}$ in length [15].

The contractile units of skeletal muscle are composed of grouped and organized myofilaments, called sarcomeres. These myofilaments are actin and myosin proteins (70-80\% of the total proteins present). Myosin is the main driver of the muscle fiber and is present in a total of eleven sarcomere myosin genes, but only a few can be described in humans, and at least two of these genes are expressed in cardiac muscle. There are many other proteins present in the sarcomere and sarcoplasm, which act as the coupling of the processes of excitation and contraction, release of energy, structuring of the cytoskeleton, and generation of strength and power [16]. Among them, in particular, we can mention the regulatory proteins that form the calcium-dependent troponin complex, which are troponins C, I, and T. Tropomyosin plays an essential role in the activation process that leads to slippage and the creation of force, which is directly associated with the actin filament [17].

In addition to the proteins mentioned above, there are other proteins that contribute to the physiological and mechanical properties of muscle, titin, and nebulin [18]. The titin is able to bind to the $\mathrm{Z}$ disk of the sarcomere and to the myosin, to provide stability and alignment to the thick filament, and this is only possible thanks to its large width.
Nebulin proteins, on the other hand, are integrated with other proteins in the thin filaments that contain actin, in which they help to maintain the sarcomere integrity [19] and influence the cell stiffness and tension that proportionally influence the formation of myofibrils and signaling local cell . In addition, in vitro studies suggest that titin may assist in muscle contraction and strength generation [20]. In the sarcomere, disk $\mathrm{Z}$ has several proteins; among them, the one that fixes the actin myofilament is called actinin. There are other proteins that also connect the $\mathrm{Z}$ disk to the sarcolemma and the extracellular matrix, called desmin [20].

Sarcoplasm is composed of several cellular elements, among them, a transverse tubular system ( $\mathrm{T}$ tubule), the sarcoplasmic reticulum, and a mitochondrial network; based on each type of fiber, the amount of these elements can be estimated. Detailing the cellular elements above, the $\mathrm{T}$ tubule system is nothing more than an invagination of the sarcolemma and its important role in driving the nerve action potential into the cell is of utmost importance for local homeostasis [21]. This network of tubules is in contact with the exterior of the cell and ensures that the excitation can spread uniformly throughout the fiber and the change in the calcium concentration was detected by the protein Dysferlin located in the membrane of the $\mathrm{T}$ tubule system [22].

The concept that mitochondria, in isolation, provide the necessary energy for muscle fibers, according to some studies, is not applicable. It was seen that there is the formation of a three-dimensional network around the cell and generates the necessary energy for muscle action when oxygen is available [23]. In this way, some mitochondria remain close to the sarcolemma to decrease the time of diffusion of oxygen through the capillaries; thus, during aerobic exercise, when the oxygen demand increases, other mitochondria, located in the intermyofibrillar space, are recruited to supply the new demand [24].

It is well known that several neuromuscular pathologies, the practice of physical exercises, and even aging directly influence the structure and function of myofilaments and the surroundings. For example, training with resistance exercises induces the production of mitochondria through the activation of the coactivator-1a of the c-receptor, activated by the peroxisome proliferator [25]. The number and size of mitochondria increase with resistance training programs/type of aerobic exercise. On the other hand, observing muscle aging, the sarcoplasmic reticulum shows a fragmented aspect and this impairs calcium release and muscle activation, so we can understand why there is muscle weakness in this population, specifically [26].

Due to the heterogeneity of human skeletal muscle in the biochemical, mechanical, and metabolic phenotypes of the individual fibers, it is possible to highlight the presence of different muscle fibers with different properties with each one specifically imposed by its respective motor neuron [27]. Through this, several physiological properties of muscle allow the plasticity capacity of the muscle according to various metabolic and mechanical demands, such as the architecture of capillary supply networks, which varies according to the type of fiber [28]. 
The three basic ways of obtaining energy for muscle fiber are the stocks of ATP and CP, anaerobic glycolysis, and oxidative phosphorylation. This obtaining in the form of ATP is of extreme importance, because according to the metabolic pathway, the production of energy varies and this must supply the energy requirement of the muscle during the period and the intensity of the activity or exercise [26].

Muscle contraction is related to the extension of the development of the sarcoplasmic reticulum, so that its contraction speed is directly proportional to this development, looking from another angle, or the oxidative capacity also directly influences this speed, but it is more observed in fatigue. The most used classifications for muscle in adults are three types of fibers: type I (slow, oxidative, and fatigue resistant), IIA (fast, oxidative, and intermediate metabolic properties), and IIx (fastest, glycolytic, and fatigable) [26, 27].

In the muscle, an activity that uses the stocks of ATP and $\mathrm{CP}$ assists high-intensity short-duration (few seconds) activities because the reserves in muscle fibers are just few. Looking into anaerobic glycolysis, it produces ATP quickly to sustain muscle actions for a couple of minutes but the end products $\left(\mathrm{H}^{+}\right.$and lactate $)$are associated with muscle fatigue and consequently damage the muscle. Eventually, the energy obtained by oxidative phosphorylation is carried out within the mitochondrial network, which is able to supply the energy demand for an intense activity or activity lasting minutes and even hours [28-30].

Obtaining the raw material for energy production can be done through carbohydrates and free plasma fatty acids and muscle triglycerides, in addition to the use of amino acid metabolism, but the percentage obtained is small compared to the energy production total $[31,32]$.

\section{Muscle Fatigue}

Muscle fatigue is usually defined as a loss of strength or power in response to contractile activity. These can occur as a result of injury or physiological or pathological adaptations [33].

In order to understand the nature of skeletal muscle fatigue, we must take into account external factors such as injuries and disuse that somehow influence the fatigue mechanism and the internal factors, which include cell signaling, vascular function, neurophysiology, bioenergetics, and molecular mechanics $[34,35]$.

Observing the loss of maximum strength or capacity to generate energy during a muscle contraction, this would be a physiological response to all muscle contractions; however, in the shortest, this cannot occur [36].

The contractions can be sustained or repetitive, and the intensity of these contractions can vary from submaximal to maximum, and from a mechanical point of view, they can be concentric, eccentric, and isometric [37, 38]. That way, according to researchers, the magnitude of loss of force or power in response to fatigue in the muscle can occur in a continuous way or only for a few moments [39].

Following this line of thought, quantifying fatigue as a single continuous contraction or a series of contractions with submaximal tension, further studies are needed. However, the study of fatigue recovery proves to be valuable, in particular, for detecting and understanding low-frequency fatigue (LFF) associated with loss of strength due to low activation frequencies and failure of the excitation and contraction coupling (ECC) of skeletal muscle [40-43].

In general, the causes of fatigue vary widely, depending on the model studied, the experimental conditions, and the tasks imposed on the muscle. In in vitro studies, it is typical to manipulate the conditions to directly determine the cause(s) of the contractile failure and fatigue is quickly observed as the drop in strength or power of a single cell or group studied. In situ studies also usually use this approach, to mimic physiological conditions and compare them by proceeding in more basic ways compared to the in vitro study.

In vivo, usually, the mechanisms of muscle fatigue magnitude vary according to the animal model and the task imposed, this is called "task specificity," and to demonstrate these mechanisms, it is common to use approaches that can cover and evaluate directly and indirectly the location(s) of failure in muscle strength and power [44-47].

\section{Fatigue in Cells}

Studies using a material that mimics fine muscle fibers to observe motility in vitro have provided insights into how actin (thin filament) interacting with myosin (thick filaments) is capable of generating strength, speed, and power [48-50]. From these studies, it was possible to observe that the main stages related to fatigue are the transition from the state of low strength to the state of high strength of the actin-myosin (AM) cross-bridge and the step of dissociation of adenosine diphosphate (ADP) from the cross-bridge AM. The first stage would be associated with the release of inorganic phosphate $(\mathrm{Pi})$ and hydrogen $\left(\mathrm{H}^{+}\right)$ions; this stage is being considered as limiting because the rate of force development and the force inhibition site immediately begin to accumulate these ions and fatigue starts during the exercise, being of high or low intensity $[45,51]$. It has been known for years that a high rate of ATP utilization accelerates the reaction of creatine kinase $(\mathrm{CK})$ and this can be seen in the last step, the release of ADP, in which the loaded contractions limit the speed of the AM cross-bridge cycle and therefore the speed of the fiber [52].

Due to the high turnover of ATP and the increase in anaerobic metabolism, as a result of the intense contractile activity, $\left[\mathrm{H}^{+}\right]$also increases, causing the decrease in intracellular $\mathrm{pH}$ in fast glycolytic fibers (FG) from 7.0 to 6.2 and for the end resulting in the decline of cellular phosphocreatine (Pi) $[45,53]$. However, other studies indicate that the increases of Pi decrease the isometric strength and fiber stiffness proportionally, indicating that the cross-bridge strength remains constant and that the strength decline is directly connected with the transition period from a bonding state of the fibers and these are also affected by the concentration of $\mathrm{Pi}$ and $\mathrm{H}^{+}[52,54-56]$.

Adversely, studies show that a low $\mathrm{pH}$ in the presence of $\mathrm{Ca}^{2+}$ decreases the strength and this may be related to the hypothesis that a high $\left[\mathrm{H}^{+}\right]$limits the amount of highstrength AM cross-bridges, inhibiting the direct velocity 
constant for the transition from the weak to the strong link state of the cross-bridge AM [57-59].

The Westerblad and Allen studies demonstrated that when the fast fibers of the mouse flexor digitorum brevis (FDB) are stimulated in vitro, the initial decline in strength occurs before any detectable change in intracellular $\left[\mathrm{Ca}^{2+}\right]$ $[60,61]$. The hypothesis of some authors was that the early loss of strength was mediated by increased pi, which was confirmed by the observation that fibers isolated from CK knockout mice, which when stimulated, did not show an increase in pi or loss of strength during the initial phase of muscle contraction $[62,63]$.

In the stimulus phase, with the high contraction rate, it was observed that the initial drop in strength would be mediated by the combined effects of the increase in $[\mathrm{Pi}]$ and $\left[\mathrm{H}^{+}\right]$ and that the effects of these ions on the myofilaments have been shown to involve additives that involve a direct inhibition of strength and reduced sensitivity to $\mathrm{Ca}^{2+}$ and that at the beginning of fatigue, the amplitude of intracellular $\mathrm{Ca}^{2+}$ is high, causing local sensitivity to be impaired and preventing fatigue from ceasing [62-64].

However, a subsequent decline in the amount of $\mathrm{Ca}^{2+}$ that had been released by the sarcoplasmic reticulum (RS) and was impairing local sensitivity causes muscle fatigue as the muscle needs to recover from this uncoordinated imbalance, resulting in more loss of strength during peak saturation and less close to physiological temperatures compared to muscle temperatures that did not contract $[50,65]$.

It is important to note that studies have shown that the $\left[\mathrm{Ca}^{2+}\right]$, necessary to elicit half the maximum strength in the muscle of mice, was significantly increased by $30 \mathrm{mM}$ pi and that the effect was two times greater on slow fibers and was performed at temperatures of $30^{\circ} \mathrm{C}$ and $15^{\circ} \mathrm{C}$ [66]. The mechanism of sensitivity to $\mathrm{Ca}^{2+}$ is not yet fully understood; however, at a $\mathrm{pH}$ of approximately 6.2, it is partially mediated by the competitive inhibition of $\mathrm{Ca}^{2+}$ binding to troponin- $\mathrm{C}$ $[67,68]$.

One factor that contributes to the certain change in the ratio of $\left[\mathrm{Ca}^{2+}\right]$ and strength is the decline in coarse filament cooperative, which is a direct result of the reduced number of high-strength cross-bridges [69-71]. In addition to the high $\left[\mathrm{H}^{+}\right]$, the micromolar increases in cell ADP, due to intense contractile activity, depress the fiber speed, but the strength increases; this is probably due to the increase in the amount and type of cross-bridges in the high-strength peaks, these being cross-bridges AM-ADP-Pi, and crossbridges AM-ADP [72, 73]. The most important role for increases in cellular ADP in eliciting fatigue seems to be related to the inhibition of the $\mathrm{Ca}^{2+}$ pump present in the sarcoplasmic reticulum, causing direct effects on the AM crossbridge.

Looking at the effects of low $\mathrm{pH}$ in conjunction with high pi and high [ADP], on slow fibers and fast fibers, it is not entirely clear how it can influence fatigue [74-77]. However, recent studies have shown that the effects of low $\mathrm{pH}$ and high $\mathrm{ADP}$ and pi have been investigated at the molecular level using the in vitro motility assay to assess the slip speed of actin filaments without the regulatory proteins tropomyosin and troponin in myosin $[78,79]$.
To confirm that using single-fiber studies, the high Pi had no effect on the sliding speed, while at $\mathrm{pH} 6.4$, the speed of the actin filament showed a $36 \%$ reduction. The increase in ADP from a low resting value of $0.02 \mathrm{mM}$ to a fatigue level of $0.3 \mathrm{mM}$ caused an $18 \%$ drop in filament speed and with phosphorylation of the $\mathrm{N}$-terminal region of the myosin light chain demonstrating that the inhibition increased to $34 \%$ $[79,80]$.

Thus, both high $\left[\mathrm{H}^{+}\right]$and ADP seem to decrease the sliding speed of the filament without load, increasing the affinity of ADP for the myosin head, thus decreasing the rate of ADP release. Besides that, the additional inhibition of speed caused by phosphorylation of the $\mathrm{N}$-terminal region of the myosin regulatory light chain can be explained by the high affinity for ADP observed in phosphorylated myosin compared to nonphosphorylated myosin.

This suggests that, although high ADP can reduce the maximum shortening speed without load, ADP may have little or no effect on fiber speeds during peak power generation at the high intensity of force. However, it is worth mentioning that phosphorylation in the $\mathrm{N}$-terminal region of the myosin light chain reduced the inhibitory effects of conditions similar to fatigue on the decrease in speed by only $28 \%$ [81-83].

\section{Excitation-Contraction Coupling Failure}

The first step for excitation-contraction (ECC) coupling to occur is the generation and propagation of the sarcolemma (SL) action potential and the proper functioning of the neuromuscular junction in nonfatigued muscle cells. It is well known that the SL membrane potential at rest is approximately $-80 \mathrm{mv}$ and, during activation, the peak action potential approaches $+20 \mathrm{mv}$. The duration of the action potential is short, varying from 1 to 1.5 milliseconds (ms), and the membrane is capable of responding to stimulation frequencies even greater than $150 \mathrm{~Hz}$ [84-87].

With the development of fatigue induced by high rates of muscle contraction, the surface membrane potential, both at rest and in action, demonstrates characteristic changes, as the resting potential becomes depolarized in 10 to $20 \mathrm{mv}$ and the height of the peak of the action potential decreases proportionately; however, the duration of the action potential becomes prolonged $[84,85]$.

The great lack of information about how and when these changes about the extent to which the tubular membrane $\mathrm{T}$ is changed and how these changes can be mitigated during exercise is still a challenge, but the hypothesis would be that the changes observed in the $\mathrm{T}$ tube should probably be greater compared to the changes observed in SL $[86,87]$.

The depolarization of the SL and $\mathrm{T}$ tube membranes interferes in two processes: first, they interfere with the generation and propagation of the action potential due to reduced activation and slower inactivation kinetics of the voltage-dependent $\mathrm{Na}^{+}$channels. Second, they interfere with the inactivation of the intramembranous $\mathrm{T}$ tubular protein, more specifically the voltage sensor, called the 1,4-dihydropyridine receptor (DHPR), obtaining the reduction in the peak of the action potential as a direct result of the 
inactivation induced by the depolarization of the voltageregulated $\mathrm{Na}^{+}$channels and, now, by the reduced electrochemical gradient and inducing the influx of $\mathrm{Na}^{+}$in the $\mathrm{T}$ system, so that the extracellular $\left[\mathrm{Na}^{+}\right]$decreases and intracellular $\left[\mathrm{Na}^{+}\right]$increases [88-90].

For inactivation of the $\mathrm{Na}^{+}$channel and DHPR, depolarization is necessary if the cell has an intracellular $\left[\mathrm{K}^{+}\right]$reduction and an extracellular $\left[\mathrm{K}^{+}\right]$increase. Studies have shown that small increases in $\left[\mathrm{K}^{+}\right]$increase the subtetan strength, while large increases reach a critical level where it causes tetany and an abrupt decrease in the contraction force. Besides that, the malfunction of the $\mathrm{Na}^{+} \mathrm{K}^{+}$pump may result in unregulated $\mathrm{pH}$-free energy of ATPase hydrolysis by increasing ADP/Pi intracellular and extracellular $[91,92]$.

In order for the processes to work correctly, the following are required: maintaining the ideal rate of activation of motor activity, diversified recruitment of motor units carried out in the CNS and $\beta$-adrenergic stimuli, stimuli for the $\mathrm{Na}^{+} \mathrm{K}^{+}$ pump to function, and an increase in $\left[\mathrm{Cl}^{-}\right]$to control the influx of $\mathrm{K}^{+}$to prevent it from reaching a critical level, resulting in fatigue [93-95].

Checking the amount of $\mathrm{K}^{+}$used by muscle cells during contraction and the amount of efflux released by the sarcolemma during action potentials, we can conclude that the account is far from closing. Thus, studies suggest that the depolarization observed in fatigued muscle cells is the result of the effects of high $\mathrm{K}^{+}$contractions, both intracellular and extracellular, and of the increase in their conductance. The increase in $\mathrm{K}^{+}$conductance can cause the activation of $\mathrm{K}^{+}$ channels, which depend on ATP or dependent on $\mathrm{Ca}^{2+}$, and the activation of these channels can directly influence the local $\mathrm{pH}$, making it more basic, creating a cascading effect that would contribute to fatigue by cell depolarization or an attempt to return homeostasis [96-98].

Studies suggest that the infusion of nonspecific antioxidant $\mathrm{N}$-acetylcysteine prolongs fatigue time and reduces the decline in $\mathrm{Na}^{+} \mathrm{K}^{+}$pump activity by approximately half, but the mechanisms of pump inactivation are not yet known; however, data suggest it that can be related with reactive oxygen species (ROS) [99].

Studies suggest that the main evidence that disturbances in eccentric contraction (ECC) contribute to fatigue is the low transient $\mathrm{Ca}^{2+}$ amplitude and that the greatest decline in $\mathrm{Ca}^{2+}$ release tends to occur late in fatigue. From this, we can observe that changes in the amplitude of $\mathrm{Ca}^{2+}$ also influence the strength, because when inducing metabolic factors signaled by the concentration of $\mathrm{Ca}^{2+}$ in $\mathrm{CPB}$, fatigue becomes early and is characterized by an increase in ATP turnover during the initial stage of contractile activity and consequently by an increase in pi and $\mathrm{H}^{+}$. Thus, so that there is a release of $\mathrm{Ca}^{2+}$ by $\mathrm{SL}$, it has become quantitatively more important in the process of developing fatigue independently if the $\mathrm{Ca}^{2+}$ ions act on the AM cross-bridge $[97,100]$.

Furthermore, there is strong evidence that $\mathrm{Ca}^{2+}$ plays an important role in cell signaling that triggers fatigue; however, the nature and how it occurs are still unknown. Studies suggest that in ECC, fatigue can be compensated by activating the $\mathrm{Ca}^{2+} /$ ATPase pumps present in the $\mathrm{T}$ tubes, in which they can move the $\mathrm{Ca}^{2+}$ from the cytoplasm to the extracellular space; from that, it is expected that local factors can activate mechanisms to correct this deregulation, such as the activation of the local $\left[\mathrm{Ca}^{2+}\right]$ pumps due to the modification of the local $\mathrm{pH}$, and thus inhibit the activity of ATPase. However, $\left[\mathrm{Ca}^{2+}\right]$ can interfere with DHPR and thus decrease the likelihood of ATPase inactivation, consequently changing the threshold of the action potential in the lumen of the $\mathrm{T}$ tube to increasingly positive values, making it deeply difficult for the muscle to leave the stage of contraction for relaxation [101-103].

Once knowing that recovery from fatigue usually occurs within minutes to an hour, we must understand that some studies theorize that part of the fatigue problem is actually related to cell signaling, more precisely, in the direct inhibition of the $\mathrm{Ca}^{2+}$ channel released by SL, called RyR1, because the content of intracellular $\mathrm{Ca}^{2+}$ depends on the activity of this channel, both for entry and removal, mainly in fast fibers. The permeability of the channel is directly regulated by $\mathrm{Ca}^{2+}$ already released in the SR, so that the ion itself, with the smallest fluctuation in concentration, regulates the RyR1 channel [104, 105].

Beyond that, considering that the intensity of the force is intracellular $\left[\mathrm{Ca}^{2+}\right]$ related and that in turn depends on the release of $\mathrm{Ca}^{2+}$ and the self-regulation of some channels for removal or influx, it is important to note that the decrease in $\left[\mathrm{Ca}^{2+}\right]$, even if is it physiological, tends to prolong the relaxation period, the opposite being also possible, and the increase in $\left[\mathrm{Ca}^{2+}\right]$ tends to prolong the contractile period of the fibers, even when the reduction of the $\mathrm{Ca}^{2+}$ of the SR during the contractile activity remains due to the binding of increased $\mathrm{Ca}^{2+}$ intracellular fast fiber proteins and the SR pump, thus consequently removing more slowly. In summary, the cell signaling that controls the period and the place where $\mathrm{Ca}^{2+}$ must be maintained during the contraction time and the relaxation time after tetanus contraction in the muscle are essential to understand muscle fatigue [106, 107].

Comparatively, the mechanism for the development of muscle fatigue also depends on the amount of ATP recruited by the muscle, from which it will then be degraded into $\mathrm{ADP}+\mathrm{pi}$, as well as the extent of phosphocreatine depletion. Studies suggest that muscle fibers have the ability to sustain ADP decline without opening $\mathrm{Ca}^{2+}$ channels and flooding the muscle with these ions, so that action potentials with $0.5 \mathrm{mM}$ cell decline did not activate $\mathrm{Ca}^{2+}$ release. However, when injected with $\mathrm{Mg}^{2+}$ ion in the declining action potential, an inhibition of $\mathrm{Ca}^{2+}$ channels was observed, due to the competition of intracellular $\mathrm{Mg}^{2+}$ by ATP, resulting in the fall of free ATP, which was possible to be released after intense exercise [108, 109].

\section{Fatigue in Organs}

Fatigue occurs in whole muscles when there is a loss of peak strength, speed, and power, in which the time course of change in function depends on the intensity of activation and the composition of the type of muscle fiber [92, 109]. The human body has some muscles made up of slow muscle fibers, so they are called slow muscles, such as the sole of the calf. These fibers are composed mainly of slow type I or slow 
oxidative fibers, that is, they generate ATP mainly from oxidative phosphorylation and are kept tonically active and are extremely resistant to fatigue. On the other hand, muscles made up of fast fibers usually have greater capacity to obtain ATP from glycolysis and other energy sources, are not kept tonically active, and are not resistant to fatigue $[79,96]$.

Going deeper into the types of fibers present in the human body. There are two types of fast fibers: IIa or fastoxidizing glycolytic fibers and IIx or glycolytic fibers. In addition to the hybrid fast fibers that contain myosin are IIa and IIx. The hybrid fiber IIx has the highest maximum speed and glycolytic capacity, while the hybrid fiber IIa has properties between fast IIx and slow type I fibers. Additionally, there is a third fast type IIb fiber, which is the fastest of all the fibers, but is expressed, in extremely inactive muscles [108, 110].

Studies have shown that understanding the isometric contraction properties before and after fatigue has helped to identify cell fatigue sites. For example, postfatigue muscle contractions show reduced muscle tension and prolonged contraction and relaxation times. The duration of the contraction depends on the detachment rate of the AM crossbridge and the duration of the transient intracellular $\mathrm{Ca}^{2+}$; therefore, the prolongation of fatigue-induced contraction is an indication that the $\mathrm{Ca}^{2+} / \mathrm{ATP}$ ase reuptake by the SR may have been inhibited; note as well that the duration of relaxation after a peak of contraction in tetany is limited by the activity of the $\mathrm{Ca}^{2+} / \mathrm{ATPase} / \mathrm{SR}$ pump $[50,105]$.

According to studies that analyzed the initial phase of relaxation of a muscle in tetany, the lengths of the sarcomere remain constant and it is believed that the relaxation rate depends directly on the detachment rate of the AM crossbridge, so that this phase showed a longer fatigue time compared to the second relaxation phase and should probably be limited by the activity of the $\mathrm{Ca}^{2+} / \mathrm{ATPase} / \mathrm{SR}$ pump [23].

Another point to be considered would be that the development of fatigue would be a force-frequency relationship. If the strength continuously decreases and relatively less frequently compared to the high ones, a solution would be that the transient $\mathrm{Ca}^{2+}$ induces in the prolongation of fatigue with low injections, however, continuous so that the muscular strength in fatigued muscles also decreases [78].

Along with the slowing of relaxation, $\alpha$-motoneuron firing rates decline with fatigue in vivo. This response is consistent with studies that observe that the optimal stimulation frequency for peak force showed a decline in muscle with fatigue [39].

Some studies show that the aim should be the muscle contractile process and should include disturbances in cross-bridge AM interactions caused by increases in $\mathrm{pH}$ and $\mathrm{Pi}$ and alterations in SR function or in the $\mathrm{Ca}^{2+} / \mathrm{ATPase}$ pump, besides the changes that can occur in cross-bridge AM. Therefore, the force, velocity, and power all are reduced. In addition, the hydrolysis of ATP produces an increase in free $\mathrm{Mg}^{2+}$ and inhibition of the RyR1 and $\mathrm{Ca}^{2+}$ release [106].

It is well known that in cases of prolonged exercise, fatigue is inevitable, as this is correlated with muscle glycogen depletion and hypoglycemia. Currently, studies are needed to explain this mandatory carbohydrate oxidation; it is hypoth- esized that the decrease in muscle glycogen and the increased dependence on fat oxidation end up limiting the ability of mitochondria to provide important components for oxidative phosphorylation such as NADH, before the muscle suffers; in addition, it was also observed that glycogen has a greater affinity with DHPR and RyR1, thus making the alternatives to meet the need for the muscle obsolete $[102,111]$.

A reduced uptake of $\mathrm{SR} \mathrm{Ca}^{2+}$ without alteration in ATPase activity suggests a decoupling of the transport or leaking vesicle, through which $\mathrm{Ca}^{2+}$ escapes into the intracellular medium and changes the concentration and local $\mathrm{pH}$. Another organelle that can be damaged due to prolonged physical exercise would be the mitochondria, in which studies indicate that it may present some edema, but there is no evidence that it can impair its function; however, it was observed that the fibers showed some wear after prolonged exercise $[105,109]$.

The oxidative phosphorylation that occurs in the mitochondria produces ATP and consumes $\mathrm{O}_{2}$; this process is also capable of generating ROS, such as hydrogen peroxide $\left(\mathrm{H}_{2} \mathrm{O}_{2}\right)$ and superoxide anion $\left(\mathrm{O}_{2}^{-}\right)$. The rate of production of ROS increases according to the intensity of work and the rate of respiration in skeletal muscle, and it is commonly recognized that ROS play a role in muscle fatigue by the oxidation of critical cellular proteins, such as the $\mathrm{Na}^{+} \mathrm{K}^{+}$pump, myofilaments, DHPR, and RyR1. The oxidation of ROS at critical RyR1 cysteine residues and/or myofibril serine groups can assist in the development of low-frequency fatigue and inhibit the release of $\mathrm{Ca}^{2+}$ from SR and the sensitivity of $\mathrm{Ca}^{2+}$ in myofibrils $[91,103,112]$.

It is believed that there is a mechanism that involves a structural alteration of the $\mathrm{Ca}^{2+} \mathrm{SR}$ release channel and/or associated proteins, since the amplitude of the $\mathrm{Ca}^{2+}$ transient is decreased for all stimulus frequencies, so that the concentration ratio of $\mathrm{Ca}^{2+}$ and strength is increasingly observed, and it can be concluded that $\mathrm{Ca}^{2+}$ mediators probably involve calmodulin (CaM), calcium-activated proteases, or ROS [64, 89, 104].

Ryr1 is part of a multiprotein complex that includes proteins involved in phosphorylation/dephosphorylation, linked to different types of cell signaling, such as cAMP-dependent protein kinase (PKA), Ca-Calmodulin-dependent protein kinase (CaMKII), phosphodiesterase-4-D-3 (PDE4D3), protein phosphatase 1 (PP1), the $\mathrm{Ca}^{2+}$ binding protein $\mathrm{CaM}$, and modulation of $\mathrm{Ca}^{2+}$ activation of the channel $[23,105,113]$.

It is well established that CaM plays a dual role in the regulation of the $\mathrm{Ca}^{2+}$ in SR release channels. CaM binding activates or inhibits the opening of the $\mathrm{Ca}^{2+}$ channel in the cytoplasm whose concentration is low and high. In a nonfatigued muscle fiber, this process probably contributes to the cyclic activation and inactivation of the release channel. There is no evidence linking $\mathrm{Ca}^{2+}$ with $\mathrm{CaM}$ to an altered RyR1 function. However, there is a possibility that the elevated cytoplasmic $\mathrm{Ca}^{2+}$ associated with fatigue leads to an altered CaM binding, so that the channel becomes more difficult to activate. The increase in cytoplasmic $\mathrm{Ca}^{2+}$ can lead to prolonged elevation of CaMKII and cause excessive phosphorylation of DHPR and/or RyR1. Looking from another point, prolonged $\beta$-adrenergic activity with exercise can also 
lead to an increase in PKA activity and result in hyperphosphorylation of RyR1. In addition, the inhibition of the PP1 and/or PDE4D3 protein can also lead to excess phosphorylation of RyR1, which can directly reduce the probability of its opening or mediate the dissociation of the stabilizing protein from the FKBP12 channel $[7,48,106]$.

The exact mechanisms and relative importance of RyR1 and the $\mathrm{Ca}^{2+} / \mathrm{ATPase} / \mathrm{SR}$ pump are not completely understood and represent an important area for future research $[78,102,107]$.

\section{Photobiomodulation}

Low-level laser therapy (LLLT) or laser therapy has been used for more than 40 years. The idea came up in 1960 after the invention of the laser, making it a widespread treatment with a variety of clinical applications. Scholars of the time decided to use different tools and models to be used according to their functions, the expressions like "photobioactivation" and "biostimulation" are often related to the stimulation effect that the LLT was used for. However, a few years later, it was possible to verify that the LLT also has an inhibitory effect; from that, it was established to coin the term "biomodulation" [108, 110].

Therapeutic treatments are based on three principles: first, minimize inflammation, edema, and chronic disorders of the joints, brain, skin, etc; second, promote wound healing in superficial and deep tissues, etc; and third, treating neurological disorders and pain [108, 111].

Recent studies indicate that the most used wavelengths for photobiomodulation therapy (PBM) are infrared (IR) and $700 \mathrm{~nm}$ to near infrared (NIR), in which they have shown more beneficial impacts than light-red in many medical conditions $[109,111]$.

In general, the laser therapy involves portions of the electromagnetic spectrum $(390-1600 \mathrm{~nm}$ and $1013-1015 \mathrm{~Hz})$, which is red until NIR, and they are absorbed according to the specific application for each biological tissue and the appropriate wavelengths $[4,112]$.

Unlike high-power "hard" lasers, LLLT provides low energy, just enough to induce a response in body tissue. In addition, it has a wavelength-dependent shape capable of altering cell function in the absence of significant heating. Thus, LLLT is also called "soft" laser therapy or cold laser, as it has low energy without thermal effects [114, 115].

Studies show that the wide range of laser therapy includes effects at the molecular, cellular, and tissue levels and the ways in which LLLT works can vary according to different application factors [116]. For the LLLT, to produce a photobiological effect, it is necessary for the photon absorption of the laser radiation to occur; the photons are captured by the initial photoreceptor molecules, which can be endogenous or exogenous chromophores. The energy absorbed from a photon can be transferred to another molecule, which can then cause a chemical reaction without changing the temperature in the surrounding tissue and consequently triggers local biochemical reactions without any discomfort [109, 117].
Several studies have suggested that mitochondria are the cellular component most sensitive to visible light and NIR; this stimulus results in increased ATP production, increased deoxyribonucleic acid (DNA) synthesis, ROS modulation, and nitric oxygen species (NOS) and in the induction of transcription factors. In addition, PBM at red and NIR wavelengths stimulates an increase in intracellular ionic $\mathrm{Ca}^{2+}$. However, recent studies emphasize that blue $(420 \mathrm{~nm})$ and green $(540 \mathrm{~nm})$ lights are more effective in increasing intracellular $\mathrm{Ca}^{2+}$. Researchers also suggest the use of blue or green light for better interaction with light-dependent ion channels, which allows light to control electrical excitability, intracellular acidity, and calcium influx, among other processes. The most likely ion channel is the rhodopsin of the light-gated channel, because the spectrum of action of the rhodopsin family exhibits peaks in the blue-green spectral region. However, the mechanism of laser-tissue interaction has not yet been fully described [118-120].

At the cellular and molecular levels, there are still open arguments and responses about the effectiveness of lasers in producing the desired responses [121]. Photobiomodulation is a form of phototherapy, which is designed to apply light with specific wavelengths from red to NIR with output powers of up to $500 \mathrm{~mW}$. One of the great advantages of LLLT is the use of photon energy at low levels to alter biological activity without thermal reactions, since there is little increase in the temperature of the irradiated tissue, in addition to being nontoxic and nonallergic, and due to the ease of application that its study has been spreading increasingly [122].

Studies indicate that clinical treatment with LLLT in various intensities has a stimulating effect on cellular processes [123]. Recently, it has been reported that at low levels of red or infrared light, LLLT can prevent cell apoptosis; stimulate mitochondrial activity; increase in cell recruitment, proliferation, and renewal; and modulate cell metabolites. In addition, it has also been suggested that LLLT may promote changes in the cell's redox state, playing an important role in ion homeostasis and consequently in cellular activity and induce photobiostimulation processes. Besides that, preexposure of PBM has a protective effect against many external agents, such as hydrogen peroxide $\left(\mathrm{H}_{2} \mathrm{O}_{2}\right)$ and $\mathrm{UV}$ radiation $[124,125]$.

\section{Discussion}

Studies suggested that the implementation of low-level laser therapy (LLLT) may cause biomodulatory, biochemical, bioelectrical, and bioenergetic effects. That is why we can use it in the repair of fatigued muscles, muscular disorders, and improved muscle performance in specific muscles already treated with LLLT. According to [126], the experimental study with 15 volunteers including female and male stroke patients who presented with poststroke spasticity, the LLLT (diode laser, $100 \mathrm{~mW}, 808 \mathrm{~nm}$, beam spot area $0.0314 \mathrm{~cm}^{2}$, $127.39 \mathrm{~J} / \mathrm{cm}^{2} /$ point, $40 \mathrm{~s}$ ) was applied mainly in areas where spasticity was present like the rectus femoris muscle and to the vastus medialis muscle. After LLLT, intervention was observed to contribute to the increase in the recruitment of muscle fibers, reduction in the scale for pain intensity 
because of its anti-inflammatory effect in stroke patients with spasticity, time delay to the fatigue onset, improvement of muscle performance, and increase in peak torque. The study also observed that LLLT provided major breakthroughs in the treatment of muscular disorders and prevention of muscle fatigue.

The literature shows that positive results were found with a single application of LLLT on tissue regeneration and decreased neurological injury but there are not enough information about laser therapy related to spastic muscle and it shows increased resistance to passive stretching that can be explained by changes in muscle tissue properties and early onset of muscle fatigue. In addition, the authors found that the application of laser photobiomodulation in spastic muscle prior to isometric exercise contributes to the decrease in blood lactate concentration after exercise possibly because laser radiation increases microcirculation, increases metabolite removal, and prevents local ischemia. Besides, it seems that the vascular effects of PBM may be due to the nitric oxide release, leading to smooth muscle relaxation and increased peripheral microcirculation. Considering the bioenergetic effects, the LLLT application is related to mitochondrial function and light interacts with the mitochondria and promotes cellular changes that also may contribute to delay muscle fatigue [127].

Impairment of basic motor functions, such as muscle weakness in limbs affected by spasticity, leads to peripheral fatigue and impaired functionality. According to [128], the clinical use of PBM has provided major advances in the treatment of muscular disorders and prevention of muscle fatigue. Their study were structured with 10 sessions of PBMT (laser $100 \mathrm{~mW}, 808 \mathrm{~nm}, 159.24 \mathrm{~J} / \mathrm{cm}^{2} /$ point, $5 \mathrm{~J} /$ point); PBM active or placebo was associated with exoskeleton-assisted functional treatment. A double-blind, placebo-controlled sequential clinical trial was conducted with 12 healthy volunteers and 15 poststroke patients who presented upper limb spasticity. Ultimately, it suggests that the application of PBM may contribute to an increased range of elbow motion and muscle fiber recruitment, increases in muscle strength, and, hence, increases in signal conduction on spastic muscle fibers in spastic patients.

\section{Conclusion}

It could be concluded that LLLT may contribute to an increased range of muscle motion and fiber recruitment and increased strength to increase signal conduction on spastic muscle fibers in spastic patients. However, further studies are needed to understand how fatigued fibers behave in these patients, since clinical studies used different laser wavelengths and numerous illumination parameters, which influence the determination of different biological parameters.

In addition, the literature is not explicit about the application of PBM in spastic patients but that this possibility could reduce pain and fatigue regarding biochemical and neuromotor mechanisms that may represent a new therapeutic use for neurological patients.

\section{Conflicts of Interest}

The authors declare that they have no conflicts of interest.

\section{References}

[1] C. M. França, C. M. França, S. C. Núñez et al., "Low-intensity red laser on the prevention and treatment of induced-oral mucositis in hamsters," Journal of Photochemistry and Photobiology B: Biology, vol. 94, no. 1, pp. 25-31, 2009.

[2] M. T. B. R. Santos, M. da Silva Pinto, K. S. Do Nascimento, and S. C. Maciel, "Efeito da fotobiomodulação no músculo masseter de criança com paralisia cerebral: relato de caso," Revista Acta Fisiátrica, vol. 22, no. 1, pp. 39-42, 2015.

[3] C. Kara, T. Demir, and E. Özbek, "Evaluation of low-level laser therapy in rabbit oral mucosa after soft tissue graft application: a pilot study," Journal of Cosmetic and Laser Therapy, vol. 15, no. 6, pp. 326-329, 2013.

[4] T. Agrawal, G. K. Gupta, V. Rai, J. D. Carroll, and M. R. Hamblin, "Pre-conditioning with low-level laser (light) therapy: light before the storm," Dose-Response, vol. 12, no. 4, pp. dose-response.1, 2014.

[5] D.-H. Choi, J. H. Lim, K.-H. Lee et al., "Effect of 710-nm visible light irradiation on neuroprotection and immune function after stroke," Neuroimmunomodulation, vol. 19, no. 5, pp. 267-276, 2012.

[6] W. R. Frontera and J. Ochala, "Skeletal muscle: a brief review of structure and function," Calcified Tissue International, vol. 96, no. 3, pp. 183-195, 2015.

[7] M. Marini and A. Veicsteinas, "The exercised skeletal muscle: a review," European Journal of Translational Myology, vol. 20, no. 3, 2010.

[8] R. R. Wolfe, "The underappreciated role of muscle in health and disease," The American Journal of Clinical Nutrition, vol. 84, no. 3, pp. 475-482, 2006.

[9] S. B. Heymsfield, M. Adamek, M. C. Gonzalez, G. Jia, and D. M. Thomas, "Assessing skeletal muscle mass: historical overview and state of the art," Journal of Cachexia, Sarcopenia and Muscle, vol. 5, no. 1, pp. 9-18, 2014.

[10] R. Javan, J. J. Horvath, L. E. Case et al., "Generating colorcoded anatomic muscle maps for correlation of quantitative magnetic resonance imaging analysis with clinical examination in neuromuscular disorders," Muscle \& Nerve, vol. 48, no. 2, pp. 293-295, 2013.

[11] M. Fortin, T. Videman, L. E. Gibbons, and M. C. Battie, "Paraspinal muscle morphology and composition," Medicine and Science in Sports and Exercise, vol. 46, no. 5, pp. 893-901, 2014.

[12] R. S. Hikida, "Aging changes in satellite cells and their functions," Current Aging Science, vol. 4, no. 3, pp. 279-297, 2011.

[13] L. Zhao, X. Zhang, Q. Luo, C. Hou, J. Xu, and J. Liu, "Engineering nonmechanical protein-based hydrogels with highly mechanical properties: comparison with natural muscles," Biomacromolecules, vol. 21, no. 10, pp. 4212-4219, 2020.

[14] F. Macaluso and K. H. Myburgh, "Current evidence that exercise can increase the number of adult stem cells," Journal of Muscle Research and Cell Motility, vol. 33, no. 3-4, pp. 187198, 2012.

[15] A. Bareja, J. A. Holt, G. Luo et al., "Human and mouse skeletal muscle stem cells: convergent and divergent mechanisms of myogenesis," PloS one, vol. 9, no. 2, article e90398, 2014. 
[16] G. D. Thomas, "Functional muscle ischemia in Duchenne and Becker muscular dystrophy," Frontiers in Physiology, vol. 4, p. 381, 2013.

[17] C. A. Ottenheijm and H. Granzier, "Lifting the nebula: novel insights into skeletal muscle contractility," Physiology, vol. 25, no. 5, pp. 304-310, 2010.

[18] C. Gelfi, M. Vasso, and P. Cerretelli, "Diversity of human skeletal muscle in health and disease: contribution of proteomics," Journal of Proteomics, vol. 74, no. 6, pp. 774795, 2011.

[19] J. A. Monroy, K. L. Powers, L. A. Gilmore, T. A. Uyeno, S. L. Lindstedt, and K. C. Nishikawa, "What is the role of titin in active muscle?," Exercise and Sport Sciences Reviews, vol. 40, no. 2, pp. 73-78, 2012.

[20] S. M. Greising, H. M. Gransee, C. B. Mantilla, and G. C. Sieck, "Systems biology of skeletal muscle: fiber type as an organizing principle," Wiley Interdisciplinary Reviews: Systems Biology and Medicine, vol. 4, no. 5, pp. 457-473, 2012.

[21] T. R. Leonard and W. Herzog, "Regulation of muscle force in the absence of actin-myosin-based cross-bridge interaction," American Journal of Physiology-Cell Physiology, vol. 299, no. 1, pp. C14-C20, 2010.

[22] I. D. Jayasinghe and B. S. Launikonis, "Three-dimensional reconstruction and analysis of the tubular system of vertebrate skeletal muscle," Journal of Cell Science, vol. 126, no. 17, pp. 4048-4058, 2013.

[23] J. P. Kerr, C. W. Ward, and R. J. Bloch, "Dysferlin in transverse tubules regulates $\mathrm{Ca}^{2+}$ homeostasis in skeletal muscle," Frontiers in Physiology, vol. 5, p. 89, 2014.

[24] R. Dahl, S. Larsen, T. L. Dohlmann et al., "Three-dimensional reconstruction of the human skeletal muscle mitochondrial network as a tool to assess mitochondrial content and structural organization," Acta Physiologica, vol. 213, no. 1, pp. 145-155, 2015.

[25] C. R. Lamboley, R. M. Murphy, M. J. McKenna, and G. D. Lamb, "Sarcoplasmic reticulum Ca2+uptake and leak properties, and SERCA isoform expression, in type I and type II fibres of human skeletal muscle," The Journal of Physiology, vol. 592, no. 6, pp. 1381-1395, 2014.

[26] Z. Yan, V. A. Lira, and N. P. Greene, "Exercise traininginduced regulation of mitochondrial quality," Exercise and sport sciences reviews, vol. 40, no. 3, pp. 159-164, 2012.

[27] N. Weisleder, M. Brotto, S. Komazaki et al., "Muscle aging is associated with compromised $\mathrm{Ca}^{2+}$ spark signaling and segregated intracellular $\mathrm{Ca}^{2+}$ release," The Journal of Cell Biology, vol. 174, no. 5, pp. 639-645, 2006.

[28] S. Schiaffino and C. Reggiani, "Fiber types in mammalian skeletal muscles," Physiological Reviews, vol. 91, no. 4, pp. 1447-1531, 2011.

[29] A. J. Galpin, U. Raue, B. Jemiolo et al., "Human skeletal muscle fiber type specific protein content," Analytical Biochemistry, vol. 425, no. 2, pp. 175-182, 2012.

[30] E. R. Weibel, "The structural conditions for oxygen supply to muscle cells: the Krogh cylinder model," Journal of Experimental Biology, vol. 216, no. 22, pp. 4135-4137, 2013.

[31] O. Baum and M. Bigler, "Pericapillary basement membrane thickening in human skeletal muscles," American Journal of Physiology-Heart and Circulatory Physiology, vol. 311, no. 3, pp. H654-H666, 2016.

[32] S. L. Lindstedt, "Body size, time and dimensions of oxygen diffusion," Comparative Biochemistry and Physiology Part
A: Molecular \& Integrative Physiology, vol. 252, article 110847, 2021.

[33] G. R. Steinberg and B. E. Kemp, "AMPK in health and disease,” Physiological Reviews, vol. 89, no. 3, pp. 1025-1078, 2009.

[34] F. Karpe, J. R. Dickmann, and K. N. Frayn, "Fatty acids, obesity, and insulin resistance: time for a reevaluation," Diabetes, vol. 60, no. 10, pp. 2441-2449, 2011.

[35] A. Houdusse and H. L. Sweeney, "How myosin generates force on actin filaments," Trends in Biochemical Sciences, vol. 41, no. 12, pp. 989-997, 2016.

[36] D. M. Callahan, S. A. Foulis, and J. A. Kent-Braun, "Agerelated fatigue resistance in the knee extensor muscles is specific to contraction mode," Muscle \& Nerve: Official Journal of the American Association of Electrodiagnostic Medicine, vol. 39, no. 5, pp. 692-702, 2009.

[37] T. Paillard, "Effects of general and local fatigue on postural control: a review," Neuroscience \& Biobehavioral Reviews, vol. 36, no. 1, pp. 162-176, 2012.

[38] B. C. Clark and T. M. Manini, "What is dynapenia?," Nutrition, vol. 28, no. 5, pp. 495-503, 2012.

[39] S. K. Hunter, H. M. Pereira, and K. G. Keenan, "The aging neuromuscular system and motor performance," Journal of Applied Physiology, vol. 121, no. 4, pp. 982-995, 2016.

[40] M. Tieland, I. Trouwborst, and B. C. Clark, "Skeletal muscle performance and ageing," Journal of Cachexia, Sarcopenia and Muscle, vol. 9, no. 1, pp. 3-19, 2018.

[41] J. A. Kent-Braun, R. H. Fitts, and A. Christie, "Skeletal muscle fatigue," Comprehensive Physiology, vol. 2, no. 2, pp. 9971044, 2011.

[42] C. Byrne, C. Twist, and R. Eston, "Neuromuscular function after exercise-induced muscle damage," Sports Medicine, vol. 34, no. 1, pp. 49-69, 2004.

[43] D. E. Rassier and B. R. Macintosh, "Coexistence of potentiation and fatigue in skeletal muscle," Brazilian Journal of Medical and Biological Research, vol. 33, no. 5, pp. 499-508, 2000.

[44] J. A. Kent-Braun, A. V. Ng, J. W. Doyle, and T. F. Towse, "Human skeletal muscle responses vary with age and gender during fatigue due to incremental isometric exercise," Journal of Applied Physiology, vol. 93, no. 5, pp. 1813-1823, 2002.

[45] R. H. Fitts, "The cross-bridge cycle and skeletal muscle fatigue," Journal of Applied Physiology, vol. 104, no. 2, pp. 551-558, 2008.

[46] R. M. Enoka and J. Duchateau, "Muscle fatigue: what, why and how it influences muscle function," Journal of Physiology, vol. 586, no. 1, pp. 11-23, 2008.

[47] M. Cifrek, V. Medved, S. Tonković, and S. Ostojić, "Surface EMG based muscle fatigue evaluation in biomechanics," Clinical biomechanics, vol. 24, no. 4, pp. 327-340, 2009.

[48] B. M. Kluger, L. B. Krupp, and R. M. Enoka, "Fatigue and fatigability in neurologic illnesses: proposal for a unified taxonomy," Neurology, vol. 80, no. 4, pp. 409-416, 2013.

[49] S. M. Marcora and W. Staiano, "The limit to exercise tolerance in humans: mind over muscle?," European Journal of Applied Physiology, vol. 109, no. 4, pp. 763-770, 2010.

[50] D. G. Allen, G. D. Lamb, and H. Westerblad, Skeletal Muscle Fatigue: Cellular Mechanisms, Physiological reviews, 2008.

[51] P. Steinbacher and P. Eckl, "Impact of oxidative stress on exercising skeletal muscle," Biomolecules, vol. 5, no. 2, pp. 356-377, 2015. 
[52] R. Cooke, "Modulation of the actomyosin interaction during fatigue of skeletal muscle," Muscle \& Nerve: Official Journal of the American Association of Electrodiagnostic Medicine, vol. 36, no. 6, pp. 756-777, 2007.

[53] M. J. Greenberg and J. R. Moore, "The molecular basis of frictional loads in the in vitro motility assay with applications to the study of the loaded mechanochemistry of molecular motors," Cytoskeleton, vol. 67, no. 5, pp. 273-285, 2010.

[54] E. Debold, "Recent insights into the molecular basis of muscular fatigue," Medicine \& Science in Sports \& Exercise, vol. 44, no. 8, pp. 1440-1452, 2012.

[55] H. Wolfenson, A. Bershadsky, Y. I. Henis, and B. Geiger, "Actomyosin-generated tension controls the molecular kinetics of focal adhesions," Journal of Cell Science, vol. 124, no. 9, pp. 1425-1432, 2011.

[56] M. Caremani, J. Dantzig, Y. E. Goldman, V. Lombardi, and M. Linari, "Effect of inorganic phosphate on the force and number of myosin cross-bridges during the isometric contraction of permeabilized muscle fibers from rabbit psoas," Biophysical Journal, vol. 95, no. 12, pp. 5798-5808, 2008.

[57] M. Linari, M. Caremani, and V. Lombardi, "A kinetic model that explains the effect of inorganic phosphate on the mechanics and energetics of isometric contraction of fast skeletal muscle," Proceedings of the Royal Society B: Biological Sciences, vol. 277, no. 1678, pp. 19-27, 2010.

[58] T. Driss and H. Vandewalle, "The measurement of maximal (anaerobic) power output on a cycle ergometer: a critical review," BioMed Research International, vol. 2013, 40 pages, 2013.

[59] H. Westerblad and D. G. Allen, "Changes of myoplasmic calcium concentration during fatigue in single mouse muscle fibers," Journal of General Physiology, vol. 98, no. 3, pp. 615-635, 1991.

[60] B. Grassi, H. B. Rossiter, and J. A. Zoladz, "Skeletal muscle fatigue and decreased Efficiency," Exercise and Sport Sciences Reviews, vol. 43, no. 2, pp. 75-83, 2015.

[61] J. J. Wan, Z. Qin, P. Y. Wang, Y. Sun, and X. Liu, "Muscle fatigue: general understanding and treatment," Experimental \& Molecular Medicine, vol. 49, no. 10, pp. e384-e384, 2017.

[62] A. J. Dahlstedt, A. Katz, and H. Westerblad, "Role of myoplasmic phosphate in contractile function of skeletal muscle: studies on creatine kinase-deficient mice," Journal of Physiology, vol. 533, no. 2, pp. 379-388, 2001.

[63] D. G. Allen, G. D. Lamb, and H. Westerblad, "Impaired calcium release during fatigue," Journal of Applied Physiology, vol. 104, no. 1, pp. 296-305, 2008.

[64] S. P. Cairns, "Lactic acid and exercise performance," Sports Medicine, vol. 36, no. 4, pp. 279-291, 2006.

[65] A. M. Jones, D. P. Wilkerson, F. DiMenna, J. Fulford, and D. C. Poole, "Muscle metabolic responses to exercise above and below the "critical power" assessed using 31P-MRS," American Journal of Physiology Regulatory, Integrative and Comparative Physiology, vol. 294, no. 2, pp. R585-R593, 2008.

[66] H. Westerblad, J. D. Bruton, and A. Katz, "Skeletal muscle: energy metabolism, fiber types, fatigue and adaptability," Experimental Cell Research, vol. 316, no. 18, pp. 3093-3099, 2010.

[67] E. P. Debold, J. Romatowski, and R. H. Fitts, “The depressive effect of $\mathrm{Pi}$ on the force-pCa relationship in skinned single muscle fibers is temperature dependent," American Journal of Physiology-Cell Physiology, vol. 290, no. 4, pp. C1041C1050, 2006.

[68] C. R. Nelson and R. H. Fitts, "Effects of low cell pH and elevated inorganic phosphate on the pCa-force relationship in single muscle fibers at near-physiological temperatures," American Journal of Physiology-Cell Physiology, vol. 306, no. 7, pp. C670-C678, 2014.

[69] E. Debold, "Recent insights into muscle fatigue at the crossbridge level," Frontiers in Physiology, vol. 3, p. 151, 2012.

[70] G. P. Farman, E. J. Allen, K. Q. Schoenfelt, P. H. Backx, and P. P. De Tombe, "The role of thin filament cooperativity in cardiac length-dependent calcium activation," Biophysical Journal, vol. 99, no. 9, pp. 2978-2986, 2010.

[71] R. D. Mateja, M. L. Greaser, and P. P. de Tombe, "Impact of titin isoform on length dependent activation and cross-bridge cycling kinetics in rat skeletal muscle," Biochimica et Biophysica Acta (BBA)-Molecular Cell Research, vol. 1833, no. 4, pp. 804-811, 2013.

[72] A. S. Cornachione, F. Leite, M. A. Bagni, and D. E. Rassier, "The increase in non-cross-bridge forces after stretch of activated striated muscle is related to titin isoforms," American Journal of Physiology-Cell Physiology, vol. 310, no. 1, pp. C19-C26, 2016.

[73] R. A. Bassit, C. H. da Justa Pinheiro, K. F. Vitzel, A. J. Sproesser, L. R. Silveira, and R. Curi, "Effect of short-term creatine supplementation on markers of skeletal muscle damage after strenuous contractile activity," European Journal of Applied Physiology, vol. 108, no. 5, pp. 945-955, 2010.

[74] E. Prochniewicz, D. A. Lowe, D. J. Spakowicz et al., "Functional, structural, and chemical changes in myosin associated with hydrogen peroxide treatment of skeletal muscle fibers," American Journal of Physiology-Cell Physiology, vol. 294, no. 2, pp. C613-C626, 2008.

[75] W. A. Macdonald and D. G. Stephenson, "Effect of ADP on slow-twitch muscle fibres of the rat: implications for muscle fatigue," Journal of Physiology, vol. 573, no. 1, pp. 187-198, 2006.

[76] R. M. Murphy, N. T. Larkins, J. P. Mollica, N. A. Beard, and G. D. Lamb, "Calsequestrin content and SERCA determine normal and maximal $\mathrm{Ca} 2+$ storage levels in sarcoplasmic reticulum of fast- and slow-twitch fibres of rat," The Journal of Physiology, vol. 587, no. 2, pp. 443-460, 2009.

[77] S. M. Norris, E. Bombardier, I. C. Smith, C. Vigna, and A. R. Tupling, "ATP consumption by sarcoplasmic reticulum Ca2 +pumps accounts for $50 \%$ of resting metabolic rate in mouse fast and slow twitch skeletal muscle," American Journal of Physiology-Cell Physiology, vol. 298, no. 3, pp. C521-C529, 2010.

[78] S. Gehlert, W. Bloch, and F. Suhr, "Ca2+-dependent regulations and signaling in skeletal muscle: from electromechanical coupling to adaptation," International Journal of Molecular Sciences, vol. 16, no. 1, pp. 1066-1095, 2015.

[79] E. P. Debold, S. E. Beck, and D. M. Warshaw, "Effect of low pH on single skeletal muscle myosin mechanics and kinetics," American Journal of Physiology-Cell Physiology, vol. 295, no. 1, pp. C173-C179, 2008.

[80] M. Amann and J. A. Calbet, "Convective oxygen transport and fatigue," Journal of Applied Physiology, vol. 104, no. 3, pp. 861-870, 2008.

[81] O. Friedrich, M. B. Reid, G. Van den Berghe et al., The Sick and the Weak: Neuropathies/Myopathies in the Critically Ill, Physiological reviews, 2015. 
[82] M. Maffei, E. Longa, R. Qaisar et al., "Actin sliding velocity on pure myosin isoforms from hindlimb unloaded mice," Acta Physiologica, vol. 212, no. 4, pp. 316-329, 2014.

[83] M. Yamaguchi, M. Kimura, Z. B. Li et al., "X-ray diffraction analysis of the effects of myosin regulatory light chain phosphorylation and butanedione monoxime on skinned skeletal muscle fibers," American Journal of Physiology-Cell Physiology, vol. 310, no. 8, pp. C692-C700, 2016.

[84] H. Jungbluth, S. Treves, F. Zorzato et al., "Congenital myopathies: disorders of excitation-contraction coupling and muscle contraction," Nature Reviews Neurology, vol. 14, no. 3, pp. 151-167, 2018.

[85] G. Cherednichenko, R. Zhang, R. A. Bannister et al., "Triclosan impairs excitation-contraction coupling and $\mathrm{Ca}^{2+}$ dynamics in striated muscle," Proceedings of the National Academy of Sciences, vol. 109, no. 35, pp. 14158-14163, 2012.

[86] R. T. Rebbeck, Y. Karunasekara, P. G. Board, N. A. Beard, M. G. Casarotto, and A. F. Dulhunty, "Skeletal muscle excitation-contraction coupling: Who are the dancing partners?," The International Journal of Biochemistry \& Cell Biology, vol. 48, pp. 28-38, 2014.

[87] H. Manring, E. Abreu, L. Brotto, N. Weisleder, and M. Brotto, "Novel excitation-contraction coupling related genes reveal aspects of muscle weakness beyond atrophy-new hopes for the treatment of musculoskeletal diseases," Frontiers in Physiology, vol. 5, p. 37, 2014.

[88] G. Santulli, D. R. Lewis, and A. R. Marks, "Physiology and pathophysiology of excitation-contraction coupling: the functional role of ryanodine receptor," Journal of Muscle Research and Cell Motility, vol. 38, no. 1, pp. 37-45, 2017.

[89] O. Delbono, "Expression and regulation of excitationcontraction coupling proteins in aging skeletal muscle," Current Aging Science, vol. 4, no. 3, pp. 248-259, 2011.

[90] R. Zalk and S. E. Lehnart, "Modulation of the ryanodine receptor and intracellular calcium," Annual Review of Biochemistry, vol. 76, no. 1, pp. 367-385, 2007.

[91] M. J. McKenna, J. Bangsbo, and J. M. Renaud, "Muscle K', $\mathrm{Na}^{+}$, and $\mathrm{Cl}-$ disturbances and $\mathrm{Na}+\mathrm{K}+$ pump inactivation: implications for fatigue," Journal of Applied Physiology, vol. 104, no. 1, pp. 288-295, 2008.

[92] J. C. Calderón, P. Bolaños, and C. Caputo, "The excitationcontraction coupling mechanism in skeletal muscle," Biophysical Reviews, vol. 6, no. 1, pp. 133-160, 2014.

[93] A. Polster, B. R. Nelson, E. N. Olson, and K. G. Beam, "Stac3 has a direct role in skeletal muscle-type excitation-contraction coupling that is disrupted by a myopathy-causing mutation," Proceedings of the National Academy of Sciences, vol. 113, no. 39, pp. 10986-10991, 2016.

[94] M. Quinonez, F. González, C. Morgado-Valle, and M. DiFranco, "Effects of membrane depolarization and changes in extracellular $\left[\mathrm{K}^{+}\right]$on the $\mathrm{Ca}^{2+}$ transients of fast skeletal muscle fibers. Implications for muscle fatigue," Journal of Muscle Research and Cell Motility, vol. 31, no. 1, pp. 13-33, 2010.

[95] T. Clausen, "Quantification of $\mathrm{Na}^{+}, \mathrm{K}^{+}$pumps and their transport rate in skeletal muscle: functional significance," Journal of General Physiology, vol. 142, no. 4, pp. 327-345, 2013.

[96] P. Manoharan, T. L. Radzyukevich, H. Hakim Javadi et al., "Phospholemman is not required for the acute stimulation of $\mathrm{Na}^{+}-\mathrm{K}^{+}$-ATPase $\alpha 2$-activity during skeletal muscle fatigue," American Journal of Physiology-Cell Physiology, vol. 309, no. 12, pp. C813-C822, 2015.

[97] B. D. Perry, V. L. Wyckelsma, R. M. Murphy et al., "Dissociation between short-term unloading and resistance training effects on skeletal muscle $\mathrm{Na}+, \mathrm{K}+-\mathrm{ATPase}$, muscle function, and fatigue in humans," Journal of Applied Physiology, vol. 121, no. 5, pp. 1074-1086, 2016.

[98] B. Gong, D. Legault, T. Miki, S. Seino, and J. M. Renaud, "KATPchannels depress force by reducing action potential amplitude in mouse EDL and soleus muscle," American Journal of Physiology-Cell Physiology, vol. 285, no. 6, pp. C1464C1474, 2003.

[99] T. Clausen and O. B. Nielsen, "Potassium, Na+,K+-pumps and fatigue in rat muscle," The Journal of Physiology, vol. 584, no. 1, pp. 295-304, 2007.

[100] O. B. Nielsen and F. V. de Paoli, "Regulation of $\mathrm{Na}+-\mathrm{K}$ +homeostasis and excitability in contracting muscles: implications for fatigue," Applied Physiology, Nutrition, and Metabolism, vol. 32, no. 5, pp. 974-984, 2007.

[101] M. Hostrup, A. Kalsen, N. Ørtenblad et al., “ $\beta 2$-Adrenergic stimulation enhances $\mathrm{Ca} 2+$ release and contractile properties of skeletal muscles, and counteracts exercise-induced reductions in $\mathrm{Na}+-\mathrm{K}+-\mathrm{ATP}$ aseVmaxin trained men," The Journal of Physiology, vol. 592, no. 24, pp. 5445-5459, 2014.

[102] V. L. Wyckelsma, I. Levinger, R. M. Murphy et al., "Intense interval training in healthy older adults increases skeletal muscle $[3 \mathrm{H}]$ ouabain-binding site content and elevates $\mathrm{Na}$ ,$+ \mathrm{K}+$-ATPase $\alpha 2$ isoform abundance in Type II fibers," Physiological reports, vol. 5, no. 7, article e13219, 2017.

[103] V. L. Wyckelsma, B. D. Perry, J. Bangsbo, and M. J. McKenna, "Inactivity and exercise training differentially regulate abundance of $\mathrm{Na}^{+}-\mathrm{K}^{+}$-ATPase in human skeletal muscle," Journal of Applied Physiology, vol. 127, no. 4, pp. 905-920, 2019.

[104] D. Christiansen, "Molecular stressors underlying exercise training-induced improvements in $\mathrm{K}<$ sup $>+</$ sup $>$ regulation during exercise and $\mathrm{Na}<$ sup $>+</$ sup $>, \mathrm{K}<$ sup $>+</$ sup $>$ -ATPase adaptation in human skeletal muscle," Acta physiologica, vol. 225, no. 3, article e13196, 2019.

[105] D. Watanabe and M. Wada, "Fatigue-induced change in Tsystem excitability and its major cause in rat fast-twitch skeletal musclein vivo," Journal of Physiology, vol. 598, no. 22, pp. 5195-5211, 2020.

[106] S. Trappe, D. Costill, P. Gallagher et al., "Exercise in Space: Human Skeletal Muscle after 6 Months aboard the International Space Station," Journal of applied physiology, vol. 106, no. 4, pp. 1159-1168, 2009.

[107] M. Murgia, L. Toniolo, N. Nagaraj et al., "Single muscle fiber proteomics reveals fiber-type-specific features of human muscle aging," Cell Reports, vol. 19, no. 11, pp. 2396-2409, 2017.

[108] N. Ørtenblad, J. Nielsen, B. Saltin, and H. C. Holmberg, "Role of glycogen availability in sarcoplasmic reticulum $\mathrm{Ca}^{2+}$ kinetics in human skeletal muscle," The Journal of Physiology, vol. 589, no. 3, pp. 711-725, 2011.

[109] F. Ginani, D. M. Soares, and C. A. G. Barboza, "Effect of lowlevel laser therapy on mesenchymal stem cell proliferation: a systematic review," Lasers in Medical Science, vol. 30, no. 8, pp. 2189-2194, 2015.

[110] N. Ørtenblad, H. Westerblad, and J. Nielsen, "Muscle glycogen stores and fatigue," The Journal of Physiology, vol. 591, no. 18, pp. 4405-4413, 2013. 
[111] V. Eisner, G. Lenaers, and G. Hajnóczky, "Mitochondrial fusion is frequent in skeletal muscle and supports excitation-contraction coupling," Journal of Cell Biology, vol. 205, no. 2, pp. 179-195, 2014.

[112] Y. H. Wu, J. Wang, D. X. Gong, H. Y. Gu, S. S. Hu, and H. Zhang, "Effects of low-level laser irradiation on mesenchymal stem cell proliferation: a microarray analysis," Lasers in Medical Science, vol. 27, no. 2, pp. 509-519, 2012.

[113] M. J. Greenberg, T. R. Mealy, M. Jones, D. Szczesna Cordary, and J. R. Moore, "The direct molecular effects of fatigue and myosin regulatory light chain phosphorylation on the actomyosin contractile apparatus," American Journal of Physiology-Regulatory, Integrative and Comparative Physiology, vol. 298, no. 4, pp. R989-R996, 2010.

[114] F. Salehpour and S. H. Rasta, "The potential of transcranial photobiomodulation therapy for treatment of major depressive disorder," Reviews in the Neurosciences, vol. 28, no. 4, pp. 441-453, 2017.

[115] R. A. Mussttaf, D. F. Jenkins, and A. N. Jha, "Assessing the impact of low level laser therapy (LLLT) on biological systems: a review," International Journal of Radiation Biology, vol. 95, no. 2, pp. 120-143, 2019.

[116] H. Chung, T. Dai, S. K. Sharma, Y. Y. Huang, J. D. Carroll, and M. R. Hamblin, "The nuts and bolts of low-level laser (light) therapy," Annals of Biomedical Engineering, vol. 40, no. 2, pp. 516-533, 2012.

[117] M. Bayat, A. Virdi, R. Jalalifirouzkouhi, and F. Rezaei, "Comparison of effects of LLLT and LIPUS on fracture healing in animal models and patients: a systematic review," Progress in Biophysics and Molecular Biology, vol. 132, pp. 3-22, 2018.

[118] L. F. de Freitas and M. R. Hamblin, "Proposed mechanisms of photobiomodulation or low-level light therapy," IEEE Journal of Selected Topics in Quantum Electronics, vol. 22, no. 3, pp. 348-364, 2016.

[119] Y. Wang, Y. Y. Huang, Y. Wang, P. Lyu, and M. R. Hamblin, "Photobiomodulation (blue and green light) encourages osteoblastic- differentiation of human adipose-derived stem cells: role of intracellular calcium and light-gated ion channels," Scientific Reports, vol. 6, no. 1, p. 33719, 2016.

[120] J. Kulbacka, A. Choromańska, J. Rossowska, J. Weżgowiec, J. Saczko, and M. P. Rols, "Cell membrane transport mechanisms: ion channels and electrical properties of cell membranes," In Transport across Natural and Modified Biological Membranes and Its Implications in Physiology and Therapy, Springer, Cham, pp. 39-58, 2017.

[121] F. G. Basso, C. F. Oliveira, C. Kurachi, J. Hebling, and C. A. de Souza Costa, "Biostimulatory effect of low-level laser therapy on keratinocytes in vitro," Lasers in Medical Science, vol. 28, no. 2, pp. 367-374, 2013.

[122] K. M. AlGhamdi, A. Kumar, and N. A. Moussa, "Low-level laser therapy: a useful technique for enhancing the proliferation of various cultured cells," Lasers in Medical Science, vol. 27, no. 1, pp. 237-249, 2012.

[123] P. Avci, A. Gupta, M. Sadasivam et al., "Low-level laser (light) therapy (LLLT) in skin: stimulating, healing, restoring," in Seminars in Cutaneous Medicine and Surgery, p. 41, NIH Public Access, 2013.

[124] K. S. Canuto, L. P. S. Sergio, O. R. Guimarães, M. Geller, F. Paoli, and A. S. Fonseca, "Low-level red laser therapy alters effects of ultraviolet $\mathrm{C}$ radiation on Escherichia coli cells," Brazilian Journal of Medical and Biological Research, vol. 48, no. 10, pp. 939-944, 2015.
[125] L. P. D. S. Sergio, A. P. A. D. Silva, P. F. Amorim et al., "DNA damage in blood cells exposed to low-level lasers," Lasers in Surgery and Medicine, vol. 47, no. 4, pp. 361-368, 2015.

[126] M. F. das Neves, M. C. Dos Reis, E. A. de Andrade et al., "Effects of low-level laser therapy (LLLT $808 \mathrm{~nm}$ ) on lower limb spastic muscle activity in chronic stroke patient," Lasers in Medical Science, vol. 31, no. 7, pp. 1293-1300, 2016.

[127] M. C. R. dos Reis, E. A. F. de Andrade, A. C. L. Borges et al., "Immediate effects of low-intensity laser $(808 \mathrm{~nm})$ on fatigue and strength of spastic muscle," Lasers in Medical Science, vol. 30, no. 3, pp. 1089-1096, 2015.

[128] M. F. das Neves, D. C. Aleixo, I. S. Mendes et al., "Long-term analyses of spastic muscle behavior in chronic poststroke patients after near-infrared low-level laser therapy (808 $\mathrm{nm})$ : a double-blinded placebo-controlled clinical trial," Lasers in Medical Science, vol. 35, no. 7, pp. 1459-1467, 2019. 